\title{
Exigências de energia de bovinos de corte em pastejo ${ }^{1}$
}

\section{Eduardo Henrique Bevitori Kling de Moraes $^{2 *}$, Mário Fonseca Paulino ${ }^{3}$, Kamila Andreatta Kling de Moraes ${ }^{4}$, Darcilene Maria de Figueiredo ${ }^{4}$, Sebastião de Campos Valadares Filho ${ }^{3}$, Pedro Veiga Rodrigues Paulino ${ }^{3}$, Victor Rezende Moreira Couto ${ }^{5}$}

\footnotetext{
1 Projeto financiado parcialmente pelo CNPq e pela FAPEMIG.

2 Doutorando, DZO-UFV, CEP: 36570-000. Bolsista do CNPq.

3 UFV, Viçosa-MG, CEP: 36570-000. Bolsista do CNPq.

${ }^{4}$ Doutoranda, DZO-UFV, CEP: 36570-000. Bolsista da CAPES

${ }^{5}$ Mestrando, DZO-UFV, CEP: 36570-000. Bolsista do CNPq.
}

RESUMO - Objetivou-se determinar as exigências e as eficiências de utilização de energia para ganho de peso e mantença de bovinos de corte em pastejo. A área experimental foi composta de cinco piquetes de Brachiaria decumbens. Utilizaram-se 27 bovinos anelorados não-castrados, com peso vivo (PV) médio inicial de 311,0 kg e idade média de 14 meses. Três animais foram abatidos após o período de adaptação para servirem como referência para as estimativas do peso de corpo vazio (PCVZ) e da composição corporal iniciais dos animais mantidos no experimento. Dos 24 restantes, quatro foram designados ao grupo mantença com tempo de pastejo restrito para limitar o consumo de energia a nível próximo da mantença. Os animais restantes (20) foram distribuídos em quatro tratamentos: mistura mineral, autocontrole, suplemento três vezes/semana (segunda, quarta e sexta); e suplemento diariamente. A exigência líquida de energia para mantença foi estimada como o anti-log do intercepto da equação obtida pela regressão linear entre o logaritmo da produção de calor (PC) e o consumo de energia metabolizável (CEM), assim como pelo coeficiente "a” da equação de regressão exponencial entre a produção de calor e o consumo de energia metabolizável dos animais sob suplementação, juntamente com o daqueles sem suplementação e os do grupo mantença. As quantidades de energia e gordura no ganho aumentaram com o peso vivo dos animais. As exigências de energia líquida para ganho de peso de bovinos anelorados não-castrados em pastejo podem ser obtidas pela equação: $\mathrm{ER}=0,0617 * \mathrm{PCVZ}^{0,75 * G D P C V Z}{ }^{1,0564}$. O requisito energético diário para mantença foi de $64,00 \mathrm{kcal} / \mathrm{PV}^{0,75}$. A eficiência de uso da EM para mantença estimada foi de 0,64 e a eficiência de uso da EM para ganho de 0,26 .

Palavras-chave: energia líquida, nutrientes digestíveis totais, pasto, zebuínos

\section{Energy requirements of beef cattle at pasture}

\begin{abstract}
A trial involving 27 zebu bulls at pasture with initial live weight (LW) of $311.0 \mathrm{~kg}$ were conducted with the objective of determining their energy requirements. Three animals were slaughtered at the beginning of the trial, performing the reference group; four had restricted grazing time to limit the energy intake to a level close to the maintenance level. The remaining were uniformly allotted to a complete randomized design, into four treatments: mineral mix, self-feeding protein and protein suplementation three times per week (Monday, Tuesday and Friday) and daily. The net energy requirement for maintenance (Nem) was estimated as the antilog of the intercept of the equation obtained by the linear regression between the heat production logarithm (HP) and the metabolizable energy intake (MEI). The "a" coefficient of the exponential equation obtained between HP and MEI was also determined from nonsupplemented animals (mineral) and supplemented animals (protein supplementation) plus animals from the maintenance group. The amount of energy and fat in the gain increased as the body weight of the animals increased. The net energy requirements for gain $(\mathrm{Neg})$ of zebu steers can be obtained through the equation: Neg = ER = $0.0617 * \mathrm{BW}^{0.75 *} \mathrm{EBG}^{1.0564}$. The daily energy requirement for maintenance was $64.00 \mathrm{kcal} / \mathrm{LW}^{0.75}$. The estimated utilization efficiency of ME for maintenance value was 0.64 and the calculated utilization efficiency of ME for gain value was 0.26 .
\end{abstract}

Key Words: net energy, pasture, total digestible nutrients, zebu cattle 


\section{Introdução}

Quando se busca um programa de produção ininterrupto de carne que seja eficiente e competitivo, torna-se essencial eliminar as fases de baixo desenvolvimento para possibilitar aos animais produzirem continuamente, durante todo o ano. Para isso, é necessário o suprimento constante de alimento e seu equilíbrio com as exigências nutricionais dos animais.

Ainda que o conhecimento das exigências nutricionais de bovinos de corte seja importante, porque por meio delas é possível proporcionar aos animais condições adequadas para atingirem sua máxima produção, há poucas informações sobre as exigências de animais em regime de pastejo no Brasil (Zervoudakis et al., 2002; Fontes et al., 2005a,b; Fregadolli, 2005). Desta forma, percebe-se na pecuária de corte nacional falta de informações acerca das exigências nutricionais de bovinos de corte criados em pastejo.

Diferentemente da produção em confinamento, bovinos criados a pasto gastam grande parte do dia caminhando e colhendo forragem e apresentam gasto extra de energia. A atividade de pastejar pode aumentar os requerimentos de energia de bovinos criados a pasto em comparação aos confinados. No entanto, existem na literatura informações que variam desde a não-alteração (DiMarco \& Aello, 1998) até aumentos da exigência energética de mantença em torno de 50\% (Havstad \& Malechek, 1982).

Segundo Fontes et al. (2005a), as pesquisas realizadas no Brasil indicam de forma inequívoca que os requerimentos de energia para mantença de animais zebuínos são mais baixos que o valor $77,0 \mathrm{kcal} / \mathrm{PV}^{0,75}$, proposto por Lofgreen \& Garrett (1968). Considerando que as pastagens são a base de sustentação da pecuária nacional, é necessário conhecimento das exigências líquidas de energia para mantença de bovinos de corte criados nestas condições.

Assim, objetivou-se estimar as exigências líquidas de energia para mantença de bovinos anelorados criados no sistema pasto-suplemento durante os períodos das águas e de transição águas/seca.

\section{Material e Métodos}

O experimento foi conduzido no Setor de Bovino de Corte da UFV, no período de março e junho de 2004. Foram utilizados 27 bovinos de corte não-castrados, com 14 meses de idade e peso médio inicial de $311,0 \mathrm{~kg}$. Ao iniciar o experimento, foram abatidos três animais que serviram de referência no estudo da composição corporal inicial. Os animais restantes (24) foram distribuídos entre os trata- mentos: mantença; mistura mineral; autocontrole; suplemento três vezes/semana (segunda, quarta e sexta); e suplemento diariamente (Tabela 1). Nos dias de suplementação, os animais receberam 1,283 kg de suplemento (grupo com suplementação três vezes por semana) ou 0,550 kg (grupo com suplementação diária), de modo que, ao final de sete dias, cada um recebeu a mesma quantidade de suplemento (3,850 kg/animal/semana).

No grupo de mantença, foram mantidos quatro animais em pastejo restrito, para atender às exigências de mantença. Os animais foram soltos às $6 \mathrm{~h}$ e presos em curral às $10 \mathrm{~h}$, totalizando 4 horas de pastejo para ingestão de alimento em nível pouco acima da exigência de mantença (Fontes et al., 2005a). Todos os animais foram pesados ao início do experimento e posteriormente a cada 28 dias.

A área experimental foi constituída de cinco piquetes de 2,0 hectares de Brachiaria decumbens Stapf., providos de bebedouros e comedouros cobertos. Com o objetivo de reduzir a influência da variação na disponibilidade de matéria seca de pasto, os animais foram mantidos em cada piquete por sete dias. Após este período, procedeu-se ao rodízio entre os piquetes, mantendo-se a aplicação dos mesmos tratamentos aos animais.

A amostragem da forragem ingerida pelos animais foi realizada pela simulação manual de pastejo. O ensaio de digestibilidade foi realizado no início da segunda pesagem dos animais após 46 dias experimentais. A excreção fecal foi estimada utilizando-se o óxido crômico e calculada com base na razão entre a quantidade do indicador fornecido e sua concentração nas fezes. O indicador foi aplicado em dose única diária ( $15 \mathrm{~g} /$ animal) acondicionado em cartuchos de papel e introduzido, utilizando-se aplicador, diretamente no esôfago dos animais durante nove dias consecutivos. Após seis dias de aplicação, foram colhidas fezes dos animais no sétimo (8 h), oitavo (12 h) e nono (16 h) dias. As estimativas do consumo voluntário individual foram obtidas empregando-se como indicador interno a fibra em detergente ácido indigestível (FDAi).

Tabela 1 - Composição percentual dos suplementos, com base na matéria natural

\begin{tabular}{lccc}
\hline Ingrediente & \multicolumn{3}{c}{ Suplemento } \\
\cline { 2 - 4 } & Mistura mineral & Autocontrole & Freqüência \\
\hline Mistura mineral & 100 & 10 & 10 \\
Uréia/sulfato de & - & 10 & - \\
amônia (9:1) & - & - & 50 \\
Farelo de soja & - & - & 40 \\
Farelo de glúten de & & & - \\
milho (21\% PB) & - & 80 & - \\
Farelo de trigo & - &
\end{tabular}


As análises laboratoriais das amostras de pasto (Tabela 2) e fezes foram realizadas de acordo com as técnicas descritas por Silva \& Queiroz (2002), com exceção das determinações de FDN e FDA, que foram realizadas conforme métodos de Van Soest \& Robertson (1985) e Mertens (2002), respectivamente.

O abate dos animais foi realizado por concussão cerebral, seguida de secção da veia jugular, após 16 horas de jejum. $\mathrm{O}$ abate foi realizado de forma escalonada, de modo que os animais dos grupos com suplementação 3 vezes/semana, suplementação diária, autocontrole e mistura mineral foram abatidos, respectivamente, após 98, 103, 105 e 110 dias de suplementação. A cada abate foi sorteado um animal do grupo mantença para ser abatido juntamente com os demais.

Durante o abate, foram colhidas e pesadas, de cada animal, amostras de órgãos, vísceras, sangue, couro, cauda, cabeça e membros. As vísceras e os órgãos foram lavados e seus pesos somados aos das demais partes do corpo (carcaça, couro, cabeça, membros e sangue) para obtenção do peso corporal vazio (PCVZ) de cada animal.

A carcaça dos animais foi dividida em duas metades, que foram pesadas e resfriadas em câmara fria a $-5^{\circ} \mathrm{C}$ por aproximadamente 20 horas. Decorrido esse tempo, a carcaça direita foi retirada da câmara fria e totalmente dissecada, procedendo-se à separação dos tecidos muscular, adiposo e ósseo, que foram pesados. Após a moagem, as amostras foram acondicionadas em vidro, levadas a estufa a $105^{\circ} \mathrm{C}$ por 72 a 96 horas para determinação da matéria seca gordurosa (MSG) e lavadas com éter de petróleo para determinação da matéria seca pré-desengordurada (MSPD).

As amostras foram trituradas em moinho de bola para posteriores determinações de nitrogênio total (NT), extrato etéreo, conforme descrito por Silva \& Queiroz (2002), e proteína bruta, obtida pelo produto entre o nitrogênio e o fator 5,88, conforme relatado por Baldwin (1995). A gordura removida no pré-desengorduramento foi calculada pela diferença entre a matéria seca gordurosa e a matéria seca pré-desengordurada, cujo resultado foi adicionado aos valores de extrato etéreo residual na MSPD, para determinação do teor total de gordura. Utilizando-se os teores de proteína e extrato etéreo na MSPD e o peso da amostra submetida ao pré-desengorduramento, foram determinados os teores de proteína e extrato etéreo na matéria natural.

A relação entre o PCVZ e o peso vivo dos animaisreferência foi utilizada para a estimativa do peso corporal vazio inicial dos animais mantidos em alimentação. Foram sorteados dois animais representantes de cada grupo para retirada de amostras da cabeça e de um membro anterior e outro posterior, para separação física de músculos, gordura, ossos e couro.

Os conteúdos corporais de gordura e proteína foram determinados por meio das concentrações desses componentes nos órgãos, nas vísceras, no couro, no sangue, na cauda, na cabeça, nos pés e nos constituintes separados (gordura, músculos e ossos) da carcaça. A estimativa da energia corporal foi obtida a partir dos teores corporais de proteína e gordura e de seus respectivos equivalentes calóricos, conforme equação preconizada pelo ARC (1980). Os conteúdos de gordura e energia retidos no corpo dos animais foram estimados por meio de equações de regressão do logaritmo do conteúdo corporal de gordura ou energia em função do logaritmo do PCVZ, segundo o ARC (1980).

Equações foram construídas adicionando os valores relativos aos dos animais-referência. Derivando as equações de predição do conteúdo corporal de gordura ou energia em função do logaritmo do PCVZ, foram obtidos as exigências líquidas de energia, por kg de ganho de PCVZ, e os conteúdos de gordura, por kg de GPCVZ, a partir de equação do tipo: $Y^{\prime}=b \cdot 10^{a} \cdot X^{b-1}$, em que $Y^{\prime}=$ conteúdo de gordura no ganho ou exigências líquidas de energia; a e b = intercepto e coeficiente de regressão, respectivamente, das equações de predição do conteúdo

Tabela 2 - Composição dos suplementos e do pasto

\begin{tabular}{|c|c|c|c|c|}
\hline \multirow[t]{2}{*}{ Item } & \multicolumn{3}{|c|}{ Sistema de alimentação } & \multirow[t]{2}{*}{ B.decumbens } \\
\hline & Mistura mineral & Autocontrole & Freqüência & \\
\hline Matéria seca (\%) & 98,75 & 89,57 & 89,97 & 24,73 \\
\hline Proteína bruta (\%MS) & - & 39,84 & 33,66 & 8,91 \\
\hline Extrato etéreo (\%MS) & - & 2,42 & 1,79 & 1,21 \\
\hline Carboidratos totais (\%MS) & - & 31,84 & 48,33 & 79,83 \\
\hline Carboidratos não-fibrosos (\%MS) & - & 13,32 & 22,81 & 4,71 \\
\hline Fibra em detergente ácido (\%MS) & - & 11,50 & 11,24 & 44,15 \\
\hline Lignina (\%MS) & - & 2,69 & 1,62 & 4,48 \\
\hline
\end{tabular}


corporal de gordura no ganho, exigências líquidas de energia; $\mathrm{X}=$ PCVZ $(\mathrm{kg})$.

Para conversão do peso vivo em peso corporal vazio, dentro do intervalo de pesos incluído neste estudo, calculou-se a correlação entre o PCVZ e o peso vivo dos animais sob suplementação. Para conversão das exigências para ganho de PCVZ em exigências para ganho de PV, utilizou-se o fator obtido a partir dos dados experimentais. Foi gerada uma equação de regressão entre a energia retida (ER) e o ganho diário de PCVZ (GDPCVZ), para determinado PCVZ, conforme preconizado pelo NRC (2000).

As exigências de energia metabolizável para mantença (EMm) foram estimadas como a relação entre a energia retida (ER, Mcal $/ \mathrm{kg} P C V Z^{0,75}$ ) e o consumo de energia metabolizável (CEM, Mcal/kg $\mathrm{PCVZ}^{0,75}$ ), segundo o modelo: ER $\left(\mathrm{Mcal} / \mathrm{kg} \mathrm{PCVZ}^{0,75}\right)=\beta 1 \times \mathrm{CEM}(\mathrm{Mcal} / \mathrm{kg}$ $\left.P C V Z{ }^{0,75}\right)+\beta_{0}$, em que $\beta_{1}$ representa a eficiência de uso da EM para ganho de peso. Igualando-se a ER a 0 (zero) na equação anterior, obteve-se o consumo de energia, em que a retenção de energia é nula e representa as exigências de EMm. Assim, a EMm foi obtida pela razão entre os coeficientes $\beta_{0}$ e $\beta_{1}$ da equação, citada anteriormente $\left(E M m=\beta_{0} / \beta_{1}\right)$. A relação entre energia retida e consumo de energia metabolizável foi obtida pelo método dos quadrados mínimos ordinários para todos os animais em conjunto.

A produção de calor (PC) em jejum ou as exigências líquidas de energia para mantença (ELm) foi estimada como o anti-log do intercepto da equação obtida pela regressão linear entre o logaritmo da PC e o consumo de energia metabolizável (CEM) dos animais do grupo mantença e daqueles que receberam suplemento, segundo Lofgreen \& Garret (1968). As concentrações de energia líquida das dietas foram calculadas conforme descrito por Harris (1970). Os valores de energia metabolizável da dieta foram calculados conforme o NRC (2000).

\section{Resultados e Discussão}

A relação obtida para estimativa do PCVZ a partir do peso vivo dos animais deste estudo foi: $\mathrm{PCVZ}=\mathrm{PV}^{*} 0,8877$, próxima à recomendada pelo NRC (2000), de 0,8910, e do valor de 0,8960 , obtido por Valadares Filho et al. (2006) com animais da raça Nelore em confinamento. Por outro lado, Fregadolli (2005) trabalhou com animais Nelore a pasto e observou relação de 0,8746 entre PCVZ e PV.

Para conversão das exigências para ganho de PCVZ (GPCVZ) em exigências para ganho de peso vivo (GPV), adotou-se o fator 0,9013 , ou seja, multiplicando-se as exigências fornecidas em função do ganho de peso de corpo vazio por 0,9013 para encontrar as exigências em relação ao ganho de peso vivo.

$\mathrm{O}$ teste de identidade entre os modelos, aplicado às equações de regressão do logaritmo do conteúdo corporal de gordura ou energia, em função do logaritmo do PCVZ, (Tabela 3) para a oferta ou não de suplementos, indicou não haver diferença entre os tratamentos. Neste sentido, adotou-se a equação em conjunto para a estimativa dos conteúdos corporais de gordura e energia.

O conteúdo corporal de gordura aumentou de $27,29 \mathrm{~kg}$ para $95,17 \mathrm{~kg}$ e o de energia, de 562,07 para $1.184,12$ Mcal conforme se aumentou o peso vivo dos animais (Tabela 4). Além disso, aumentaram-se os conteúdos de gordura, expressos em g/kg PCVZ, e energia, em Mcal $/ \mathrm{kg}$ PCVZ. Quando o PCVZ passou de 221,93 kg (250 kg PV) para 355,08 kg (400 kg PV), ocorreram aumentos em torno de 248,8 e $110,7 \%$, respectivamente, nos conteúdos de gordura e energia.

Resultados semelhantes foram observados por Silva et al. (2002) em bovinos criados em confinamento e por Zervoudakis et al. (2002) e Fregadolli (2005) em bovinos criados a pasto. A taxa de aumento observada neste estudo foi maior que a verificada por Fregadolli (2005), que observou aumento do conteúdo de gordura de 22,60 kg para 66,66 kg quando o peso vivo dos animais da raça Nelore aumentou de 250 para $400 \mathrm{~kg}$. Por outro lado, maiores aumentos no conteúdo de gordura em relação aos observados neste trabalho foram observados por Zervoudakis et al. (2002), o que reflete a desaceleração do crescimento do tecido muscular em detrimento ao desenvolvimento mais rápido do tecido adiposo com o aumento no PCVZ, que apresenta maior impulso de crescimento em idades mais avançadas (Berg \& Butterfield, 1979).

Com a elevação do peso vivo dos animais de $250 \mathrm{~kg}$ para $400 \mathrm{~kg}$, observaram-se aumentos de 31,6 e 117,97\% nos

Tabela 3 - Parâmetros das equações de regressão do logaritmo dos conteúdos de gordura $(\mathrm{kg})$ e energia (Mcal) no corpo vazio, em função do logaritmo do PCVZ (kg) de bovinos de corte sob pastejo

\begin{tabular}{lccc}
\hline \multirow{2}{*}{ Item } & \multicolumn{2}{c}{ Parâmetro } & $\mathrm{r}^{2}$ \\
\cline { 2 - 3 } & \multicolumn{2}{c}{ Intercepto (a) } & Coeficiente (b) \\
\hline Não-suplementados & $-5,3987$ & 2,8437 & 0,97 \\
Suplementados & $-4,9410$ & 2,6564 & 0,92 \\
Conjunta & $-4,9375$ & 2,6579 & 0,95 \\
& \multicolumn{4}{c}{ Energia } \\
Não-suplementados & $-1,2145$ & 1,6482 & \\
Suplementados & $-1,0642$ & 1,5899 & 0,97 \\
Conjunta & $-1,0519$ & 1,5854 & 0,95 \\
\hline
\end{tabular}


Tabela 4 - Conteúdos de gordura e energia corporais estimados em relação ao peso vivo e o peso de corpo vazio de bovinos de corte em pastejo

\begin{tabular}{lcccc}
\hline $\begin{array}{l}\text { Peso vivo } \\
(\mathrm{kg})\end{array}$ & $\begin{array}{c}\text { Gordura } \\
(\mathrm{kg})\end{array}$ & $\begin{array}{c}\text { Energia } \\
(\text { Mcal })\end{array}$ & $\begin{array}{c}\text { Gordura } \\
(\mathrm{g} / \mathrm{kg} \text { PCVZ) }\end{array}$ & $\begin{array}{c}\text { Energia } \\
(\text { Mcal/kg } \\
\text { PCVZ) }\end{array}$ \\
\hline 250 & 27,29 & 562,07 & 89,59 & 2,10 \\
300 & 44,30 & 750,46 & 121,21 & 2,33 \\
350 & 66,74 & 958,22 & 156,51 & 2,55 \\
400 & 95,17 & 1184,12 & 195,29 & 2,76 \\
\hline
\end{tabular}

$\mathrm{PCVZ}=\mathrm{PV} * 0,8877$.

conteúdos de gordura e nas exigências de energia no ganho de PCVZ, respectivamente (Tabela 5).

Os resultados corroboram os descritos na literatura, tanto para animais criados em confinamento (Freitas et al., 2006; Silva et al., 2002) quanto para animais em pastejo (Zervoudakis et al., 2002; Fregadolli, 2005). Segundo Berg \& Butterfield (1976), com o aumento do peso corporal, a concentração de gordura no corpo aumento elevando as exigências energéticas, como resultado do aumento no valor energético do ganho e do aumento do peso dos animais.

A taxa de aumento do conteúdo de gordura no ganho com a elevação do peso corporal dos animais deste estudo foi menor que as observadas por Freitas et al. (2006) em animais em regime de confinamento. Fontes et al. (2005b), em animais em pastejo, também encontraram menores taxas de aumento de gordura no ganho com o aumento do peso vivo dos animais em comparação a animais confinados.

O menor conteúdo de gordura em animais em pastejo em comparação a animais em confinamento é decorrente do menor nível de energia da dieta normalmente consumida por animais em pastejo em relação aos mantidos com dietas mais energéticas, comumente utilizadas em confinamento e que propiciam taxas de ganho de peso mais elevadas. Sabe-se também que o conteúdo de gordura no ganho é positivamente influenciado pela taxa de ganho de peso dos animais (NRC, 2000). Essa menor deposição de gordura corporal também pode estar relacionada à maior atividade física de bovinos manejados a pasto.

Neste estudo, para um bovino com $400 \mathrm{~kg}$ de PV e ganho de peso de 1,0 kg/dia, as exigências líquidas de energia foram estimadas em 4,21 Mcal/kg GPCVZ. Para o mesmo peso (400 kg), Fregadolli (2005) encontrou para animais Nelore requisitos líquidos de energia para ganho de 1,0 kg de PCVZ de 4,65 Mcal.

A equação de regressão desenvolvida para descrever a relação entre a energia retida (ER) e o ganho diário de PCVZ (GDPCVZ) a determinado PCVZ, foi: ER =
Tabela 5 - Exigências líquidas de energia e conteúdo de gordura no GPCVZ de bovinos de corte sob pastejo

\begin{tabular}{lcc}
\hline $\begin{array}{l}\text { Peso vivo } \\
(\mathrm{kg})\end{array}$ & $\begin{array}{c}\text { Exigência de } \\
\text { energia }(\text { Mcal/kg GPCVZ) }\end{array}$ & $\begin{array}{c}\text { Conteúdo de } \\
\text { gordura }(\mathrm{g} / \mathrm{kg} \text { GPCVZ) }\end{array}$ \\
\hline 250 & 3,32 & 238,13 \\
300 & 3,70 & 322,17 \\
350 & 4,05 & 415,99 \\
400 & 4,38 & 519,07 \\
\hline
\end{tabular}

$\mathrm{PCVZ}=\mathrm{PV} * 0,8877$

0,0617*PCVZ ${ }^{0,75 *} \operatorname{GDPCVZ}^{1,056}\left(\mathrm{r}^{2}=0,69\right)$, em que: $\mathrm{ER}=$ retenção diária de energia, expressa em Mcal. Esta equação difere da preconizada pelo NRC (2000), para um novilho de porte médio, que é igual a: ER = 0,0635*PCVZ ${ }^{0,75 *}$ GDPCVZ $^{1,097}$. Utilizando dados nacionais de diferentes estudos, Valadares Filho et al. (2006) obtiveram para machos não-castrados zebuínos ER $($ Mcal/dia $)=0,0529 *$ PCVZ $^{0,75 *}$ GDPCVZ $^{1,0996}$.

A equação encontrada neste estudo estima a energia retida de um animal com ganho de peso corporal vazio igual a 1,0 kg e PV de $400 \mathrm{~kg}$, em 5,51 Mcal/dia, superior ao estimado por Valadares Filho et al. (2006), de 4,73 Mcal/dia para machos não-castrados. Por outro lado, para o mesmo exemplo, a equação descrita pelo NRC (2000) estimaria a energia retida em 5,68 Mcal/dia. O fato de a energia retira obtida com os dados deste estudo ser inferior à encontrada pela equação proposta pelo NRC (2000) pode, em parte, ser explicado pelas menores quantidades de gordura entremeada (marmoreio) e gordura total observadas em zebuínos em relação à maioria dos taurinos, principalmente aqueles criados em pastejo.

Utilizando-se a regressão do logaritmo da produção de calor (PC), em função do consumo de energia metabolizável (CEM), em kcal/PV $\mathrm{PV}^{0,75} /$ dia e em kcal/PCVZ ${ }^{0,75} / \mathrm{dia}$, foram obtidas, respectivamente, as equações $\log$ $\mathrm{PC}_{(\mathrm{PV})} 0,75=1,8062+0,0020 * \mathrm{CEM}\left(\mathrm{r}^{2}=0,95\right)$ e $\mathrm{Log}$ $\mathrm{PC}_{(\mathrm{PCZV})} 0,75=1,8409+0,0019 * \mathrm{CEM}\left(\mathrm{r}^{2}=0,95\right)$.

Ao calcular o antilogaritmo do intercepto das duas equações, encontraram-se, respectivamente, os valores de $64,00 \mathrm{kcal} / \mathrm{PV}^{0,75} /$ dia e $69,33 \mathrm{kcal} / \mathrm{PCVZ}^{0,75} /$ dia como exigências de energia líquida de mantença (ELm) para bovinos anelorados criados em regime de pastejo. O valor estimado de Elm de 64,00 kcal/PV0,75/dia é 8,20\% inferior do valor de $69,30 \mathrm{kcal} / \mathrm{PV}^{0,75}$ recomendado pelo NRC (2000). Trabalhando com bovinos $3 / 4$ Holandês-Gir castrados, em pastagens de capim-elefante (Pennisetum purpureum, Shum.), Fontes et al. (2005a) encontraram exigências de $57,00 \mathrm{kcal} / \mathrm{PV}^{0,75} / \mathrm{dia}$ e $63,30 \mathrm{kcal} / \mathrm{kg} \mathrm{PCVZ}^{0,75}$ sendo, respectivamente, 12,3 e 9,5\% inferiores ao do presente 
estudo. O valor obtido expresso em kcal/PCVZ ${ }^{0,75} /$ dia foi maior do que o valor relatado por Paulino et al. (1999), que obtiveram o valor de 60,38 kcal/PCVZ ${ }^{0,75} /$ dia como exigência de ELm para zebuínos em confinamento. Variações nas exigências energéticas para mantença podem ser explicadas, dentre outras, pelas diferenças genéticas, composição corporal, condição fisiológica e corporal, aspectos nutricionais, sexo e raça (Solis et al., 1988).

Em comparação a animais criados em confinamento, aqueles criados em pastejo podem apresentar maiores exigências de energia para mantença. No entanto, segundo Brosh et al. (2006), essa hipótese ainda não está bem elucidada, pois existem diferenças significativas entre as informações reportadas na literatura quanto ao gasto de energia com a atividade de pastejo. Blaxter (1967), citado por Brosh et al. (2006), sugeriram que as exigências de energia para mantença aumentaram em 15,0\% em bovinos sob pastejo. Por outro lado, Osuji (1974) observaram que a atividade de pastejo pode aumentar os requerimentos de energia de ruminantes de 25,0 a 50,0\% em comparação aos animais em confinamento e que considerável parte deste aumento pode ser atribuída ao gasto energético para locomoção e colheita da forragem.

De acordo com Brosh et al. (2006), o gasto energético de bovinos criados a pasto é afetado por muitos fatores além da atividade de pastejo e que muitos destes são interdependentes. Segundo DiMarco \& Aello (2001), o custo de manutenção de animais em pastejo pode ser de 8,0 a $30,0 \%$ maior que o de animais em confinamento e que essa variação depende, fundamentalmente, das características da pastagem. Além disso, observaram que a ingestão de forragem, em alta taxa de apreensão, é a variável de maior influência no custo diário de manutenção dos animais em pastejo, enquanto a ingestão de forragem em taxa moderada de apreensão e o caminhar têm efeito menor no custo. Desta forma, com base nas observações de DiMarco \& Aello (2001) infere-se que em sistemas de produção baseados em pastagem, é fundamental o bom manejo destas durante quaisquer épocas do ano para que apresentem boa disponibilidade de forragem para capacitar os animais em selecionar uma dieta de melhor qualidade com menor dispêndio de energia com reflexos positivos sobre o desempenho.

A exigência de energia para mantença tem sido definida como o consumo diário de energia metabolizável (CEM) no qual o balanço energético do animal se torna nulo (Dawson \& Steen, 1998). Plotando-se o consumo de energia metabolizável em função da energia retida (ER), obtém-se uma equação do tipo ER = a + b CEM; em que o intercepto (b) representa a eficiência de utilização de energia metabolizável (EM) e, igualando-se aER a 0 (zero), estimam-se as exigências de EMm. Desta forma, foi construída uma equação de regressão entre a ER e o CEM dos animais em conjunto (Figura 1).

De acordo com a equação estimada, as exigências de EMm de bovinos anelorados criados a pasto seriam de $108,78 \mathrm{kcal} / \mathrm{kgPCVZ}^{0,75}$, valor adotado para animais que consomem tanto suplemento mineral quanto protéico. Valadares Filho et al.(2006) e Sainz etal.(2006), ao compilarem dados individuais de bovinos Nelore no Brasil, obtiveram exigências de EM para machos não-castrados, respectivamente, de 108,40 e 107,13 kcal $/ \mathrm{kgPCVZ}^{0,75}$. Sainz et al. (2006), ao assumirem eficiência de uso da EM média de 64\%, atestaram que o valor obtido de 107,13 kcal/kgPCVZ ${ }^{0,75}$ é

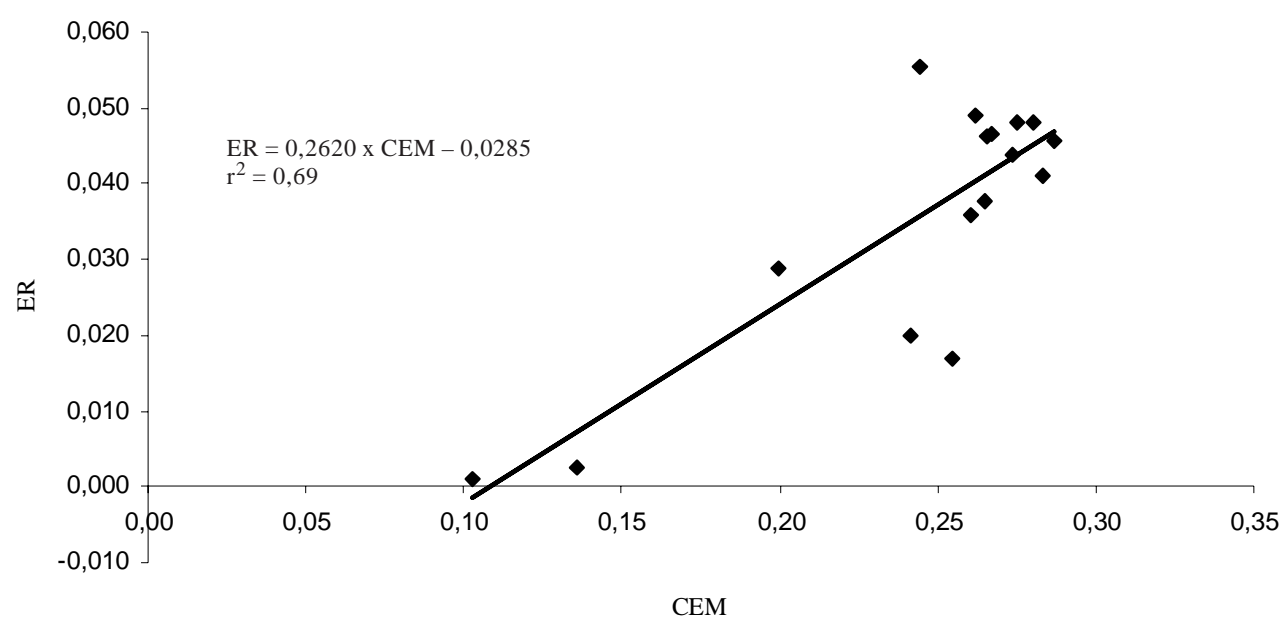

Figura 1 - Relação entre energia retida (ER) e consumo de energia metabolizável (CEM) em bovinos anelorados em pastagem, obtida pelo do método dos quadrados mínimos ordinários, para os animais em conjunto. 
praticamente idêntico ao sugerido pelo NRC (2000) para animais zebuínos. Portanto, o valor obtido neste estudo está de acordo com relatos da literatura envolvendo animais da raça Nelore.

As eficiências de uso da EM para ganho de peso $\left(\mathrm{k}_{\mathrm{g}}\right)$ e para mantença $\left(\mathrm{k}_{\mathrm{m}}\right)$ foram de 26 e $64 \%$, respectivamente. A eficiência para ganho $\left(\mathrm{k}_{\mathrm{g}}\right)$ estimada foi inferior ao valor de 0,35 recomendado por Valadares Filho et al. (2006) para animais com taxas de ganho de peso menores que $1,0 \mathrm{~kg} / \mathrm{dia}$.

Para animais 3/4 Holandês-Gir em pastejo, Fontes et al. (2005a) encontraram EMm de 99,52 kcal/lg PCVZ ${ }^{0,75}$ e eficiência de utilização da EM de 0,64. Por outro lado, Valadares Filho et al. (2006) calcularam a EMm em $108,40 \mathrm{kcal} / \mathrm{PCVZ}^{0,75} /$ dia e eficiência de utilização da EM de 0,60.

Os valores estimados neste estudo para exigências líquidas diárias de energia para mantença de bovinos em pastejo com 250 a 400 kg de peso vivo são muito próximos aos observados por Fontes et al. (2005b), para qualquer faixa de peso, em animais em pastejo (Tabela 6).

Segundo Fontes et al. (2005b), quando comparados a valores de exigência de mantença encontrados no exterior

Tabela 6 - Exigência líquida diária de energia para mantença de bovinos anelorados em pastejo

\begin{tabular}{lc}
\hline Peso vivo $(\mathrm{kg})$ & $\begin{array}{c}\text { Exigência de energia líquida } \\
\text { para mantença (Mcal/dia) }\end{array}$ \\
\hline 250 & 3,99 \\
300 & 4,57 \\
350 & 5,13 \\
400 & 5,67 \\
\hline
\end{tabular}

$\mathrm{PCVZ}=\mathrm{PV} * 0,8877$ para bovinos de raças européias, incluindo o valor de $77 \mathrm{kcal} / \mathrm{kg} \mathrm{PV}{ }^{0,75}$, proposto por Loffgreen \& Garrett (1968), os resultados obtidos no Brasil para animais zebuínos ou mestiços são mais baixos, o que está de acordo com informações do CSIRO (1990) de que as exigências de mantença de animais zebuínos são menores que dos animais taurinos.

Com o aumento do peso corporal, aumentaram as exigências de mantença de energia metabolizável, energia digestível e nutrientes digestíveis totais, seguindo tendência semelhante à observada para as exigências líquidas de energia para mantença (Tabela 7).

Considerando a eficiência de uso da EM para mantença obtida, de 0,64 , e o valor de $64,00 \mathrm{kcal} / \mathrm{PV}^{0,75}$ como requisito líquido de energia para mantença, a exigência de energia metabolizável para mantença de bovinos de corte em pastejo seria de $100,00 \mathrm{kcal} / \mathrm{PV}^{0,75}$, a de energia digestível de $121,95 \mathrm{kcal} / \mathrm{PV}^{0,75}$ e a de NDT de $27,66 \mathrm{~g} / \mathrm{PV}^{0,75}$.

As exigências líquidas de energia metabolizável ou de NDT, para as duas dietas (Tabela 8), aumentaram de acordo com o peso corporal, confirmando resultados obtidos por Silva et al. (2002) em animais não-castrados em confinamento.

Tabela 7 - Exigências diárias de energia metabolizável e energia digestível e requisitos de NDT para mantença de bovinos anelorados em pastejo

\begin{tabular}{lccc}
\hline $\begin{array}{l}\text { Peso vivo } \\
(\mathrm{kg})\end{array}$ & $\begin{array}{c}\text { Energia metabolizável } \\
(\text { Mcal/dia) }\end{array}$ & $\begin{array}{c}\text { Energia digestível } \\
(\text { Mcal/dia })\end{array}$ & $\begin{array}{c}\text { NDT } \\
(\mathrm{kg} / \mathrm{dia})\end{array}$ \\
\hline 250 & 6,23 & 7,60 & 1,72 \\
300 & 7,14 & 8,71 & 1,98 \\
350 & 8,02 & 9,78 & 2,22 \\
400 & 8,86 & 10,81 & 2,45 \\
\hline
\end{tabular}

$\mathrm{PCVZ}=\mathrm{PV}^{*} 0,8877$.

Tabela 8 - Estimativa dos requisitos de energia líquida para ganho de peso (Elg), de energia metabolizável e de nutrientes digestíveis totais (NDT), concentrações de EM da dieta e respectivas eficiências de utilização da energia metabolizável para ganho de peso $\left(\mathrm{k}_{\mathrm{g}}, \%\right)$ de bovinos de corte em pastejo

\begin{tabular}{|c|c|c|c|c|c|c|}
\hline \multirow{4}{*}{ PV (kg) } & \multicolumn{6}{|c|}{ Energia metabolizável da dieta (Mcal/kg de MS) } \\
\hline & \multicolumn{3}{|c|}{$1,81\left(\mathrm{k}_{\mathrm{g}}=0,26\right)$} & \multicolumn{3}{|c|}{$2,17\left(\mathrm{k}_{\mathrm{g}}=0,30\right)$} \\
\hline & \multicolumn{6}{|c|}{ Exigência } \\
\hline & Elg (Mcal/kg GPV) & EM (Mcal/kg GPV) & NDT (kg/kg GPV) & Elg & EM & NDT \\
\hline 250 & 2,84 & 10,94 & 3,02 & 2,84 & 9,34 & 2,58 \\
\hline 300 & 3,26 & 12,54 & 3,47 & 3,26 & 10,71 & 2,96 \\
\hline 350 & 3,66 & 14,07 & 3,89 & 3,66 & 12,02 & 3,32 \\
\hline 400 & 4,04 & 15,56 & 4,30 & 4,04 & 13,29 & 3,67 \\
\hline
\end{tabular}




\section{Conclusões}

Bovinos anelorados criados em pastejo apresentam exigências de energia líquida de mantença de 64,00 kcal/ $\mathrm{PV}^{0,75} /$ dia e 69,33 kcal/PCVZ ${ }^{0,75} /$ dia. As exigências de energia líquida para ganho podem ser obtidas pela equação: $\mathrm{ER}(\mathrm{Mcal} / \mathrm{kg})=0,0617 * \mathrm{PCVZ}^{0,75 *} \mathrm{GDPCVZ}^{1,0564}$. A eficiência de utilização da energia metabolizável para mantença $\left(\mathrm{k}_{\mathrm{m}}\right)$ é de $64 \%$ e para ganho $\left(\mathrm{k}_{\mathrm{g}}\right)$ de $26 \%$.

\section{Literatura Citada}

AGRICULTURAL RESEARCH COUNCIL - ARC. The nutrient requirements of ruminants livestock. London: 1980. 351p.

BALDWIN, R.L. Energy requirements for maintenance and production. In: BALDWIN, R.L. (Ed.) Modeling ruminant digestion and metabolism. London: Chapman \& Hall, 1995. p.148-188.

BERG, R.T.; BUTTERFIELD, R.M. New concepts of cattle growth. New York: Sydney University, 1976. 240p.

BROSH, A.; ENKIN, Z.; UNGAR, E.D. et al. Energy cost of cows' grazing activity: use of the heart rate method and the global positioning system for direct field estimation. Journal of Animal Science, v.84, p.1951-1967, 2006.

COMMONWEALTH SCIENTIFIC AND INDUSTRIAL RESEARCH ORGANIZATION - CSIRO. Feeding standards for Australian livestock-ruminants. Victoria: Australia Agricultural Council, 1990. 266p.

DAWSON, L.E.R.; STEEN, R.W.J. Estimation of maintenance energy requirements of beef cattle and sheep. Journal of Agricultural Science, v.31, p.477-485, 1998.

DiMARCO, O.N.; AELLO, M.S. Energy cost of cattle walking on the level and on the gradient. Journal of Range Management, v.51, p.9-13, 1998.

DiMARCO, O.N.; AELLO, M.S. Energy expenditure due to forage intake and walking of grazing cattle. Arquivo Brasileiro de Medicina Veterinária e Zootecnia, v.53, n.1, p.100-105, 2001.

FONTES, C.A.A.; OLIVEIRA, R.C.; ERBESDOBLER, E.D. et al. Conteúdo de energia líquida para mantença e ganho do capimelefante e mudanças na composição corporal de novilhos em pastejo, durante a estação chuvosa. Revista Brasileira de Zootecnia, v.34, n.5, p.1711-1720, 2005a.

FONTES, C.A.A.; OLIVEIRA, R.C.; ERBESDOBLER, E.D. et al. Uso do abate comparativo na determinação da exigência de energia de mantença de gado de corte pastejando capim-elefante: descrição da metodologia e dos resultados. Revista Brasileira de Zootecnia, v.34, n.5, p.1721-1729, 2005b.

FREGADOLLI, F.L. Composição corporal e exigências nutricionais de novilhos de três grupos genéticos em pastejo. 2005. 85f. Tese (Doutorado em Zootecnia) Universidade Estadual Paulista, Faculdade de Ciências Agrárias e Veterinárias, Jaboticabal, 2005.
FREITAS, J.A.; QUEIROZ, A.C.; DUTRA, A.R. et al. Composição do ganho e exigências de energia e proteína para ganho de peso em bovinos Nelore puros e mestiços, em confinamento. Revista Brasileira de Zootecnia, v.35, n.3, p.886-893, 2006.

HARRIS, L.F. Nutrition research technique for domestic and wild animal. 1.ed. Logan: 1970. paginação descontínua.

HAVSTAD, K.M.; MALECHEK, J.C. Energy expenditure of heifers grazing crested wheatgrass of diminishing availability. Journal of Range Management, v.35, p.447-450, 1982.

LOFGREEN, G.P.; GARRET, W.N.A. System for expressing net energy requirements and feed values for growing and finishing beef cattle. Journal of Animal Science, v.27, n.3, p.793-806, 1968.

MERTENS, D.R. Gravimetric determination of amylase treated neutral detergent fiber in feeds with refluxing in beakers or crucibles: collaborative study. Journal of AOAC International, v.85, n.6, p.1212-1240, 2002.

NATIONAL RESEARCH COUNCIL - NRC. Nutrient requirements of beef cattle. 7 rev. ed. Washington, DC.: National Academy Press, 2000. 242p.

OSUJI, P.O. The physiology of eating and the energy expenditure of the ruminant at pasture. Journal of Range Management, v.27, p.437-443, 1974.

PAULINO, M.F.; FONTES, C.A.A.; JORGE, A.M. et al. Exigências de energia para mantença de bovinos zebuínos não-castrados em confinamento. Revista Brasileira de Zootecnia, v.28, n.3, p.621-626. 1999.

SAINZ, R.D.; BARIONI, L.G.; PAULINO, P.V.R. et al. Growth patterns of Nellore vs. British beef cattle breeds assessed using a dynamic, mechanistic model of cattle growth and composition. In: KEBREAB, E.; DIJKSTRA, J.; BANNINK, A. et al. (Eds.) Nutrient digestion and utilization in farm animals: modeling approaches. Wallingford: Cabi Publishing, 2006. 480p.

SILVA, D.J.; QUEIROZ, A.C. Análise de alimentos: métodos químicos e biológicos. 3.ed. Viçosa, MG: Editora UFV, 2002. $165 p$.

SILVA, F.F.; VALADARES FILHO, S.C.; ÍTAVO, L.C.V. et al. Composição corporal e requisitos energéticos e protéicos de bovinos nelore, não-castrados, alimentados com rações contendo diferentes níveis de concentrado e proteína. Revista Brasileira de Zootecnia, v.31, n.1, p.503-513, 2002.

SOLIS, J.C.; BYERS, F.M.; SCHELLING, G.T. et al. Maintenance requirements and energetic efficiency of cows of different breed types. Journal of Animal Science. v.66, n.3, p.764-773, 1988.

VALADARES FILHO, S.C.; PAULINO, P.V.R.; DETMANN, E. et al. Exigências nutricionais de zebuínos no Brasil: I. Energia. In: VALADARES FILHO, S.C.; PAULINO, P.V.R.; MAGALHÃES, K.A. (Eds.) Exigências nutricionais de zebuínos e tabelas de composição de alimentos BR-Corte. 1.ed. Viçosa, MG: UFV, 2006. 142p.

Van SOEST, P.J.; ROBERTSON, J.B. Analysis of forages and fibrous foods. Ithaca: Cornell University, 1985. 202p.

ZERVOUDAKIS, J.T.; PAULINO, M.F.; DETMANN, E. et al. Conteúdo corporal e exigências líquidas de proteína e energia de novilhos suplementados no período das águas. Revista Brasileira de Zootecnia, v.31, n.1, p.530-537, 2002. 